\title{
Effects of Infestation by Rhipicephalus sanguineus on Lymphocyte Blastogenic Responses to Mitogens in Dogs
}

\author{
Hisashi INOKUMA, Takako AITA, Kouichi OHNO and Takafumi ONISHI \\ Laboratory of Veterinary Internal Medicine, Faculty of Agriculture, Yamaguchi University, Yamaguchi 753-8515, Japan \\ (Received 19 February 1998/Accepted 1 April 1998)
}

\begin{abstract}
Mitogen blastogenic responses of lymphocytes from dogs infested with adult Rhipicephalus sanguineus and the effects of salivary gland extracts (SGE) of the tick on the blastogenic responses of lymphocytes from normal dogs were studied. Infestation by $R$. sanguineus significantly suppressed concanavalin A, phyto-hemagglutinin and pokeweed mitogen responses of lymphocytes from dogs. The inhibition of lymphocyte responses of dogs in the first infestation was greater than that in the second infestation. SGE from $R$. sanguineus also suppressed all mitogen blastogenic responses of lymphocytes from healthy dogs in vitro. These suppressive effects of SGE on the blastogenic responses of PBL to mitogens were significantly inhibited by trypsin digestion. It is suggested that some proteins in SGE contribute to the suppressive effects of SGE on the blastogenic responses of peripheral blood lymphocytes from dogs. - KEY WORDS: canine, lymphocyte mitogenesis, Rhipicephalus sanguineus.
\end{abstract}

J. Vet. Med.Sci. 60(9): 1013-1016, 1998

Rhipicephalus sanguineus is the most wide spread dog tick in the world. This tick is a well known vector of many diseases of dogs, and it is also known that tick infestation itself has immune suppressive effects on the host animals [22-24]. Most of the information on immunological modulation by ixodid ticks has been obtained from experiments with cattle or with laboratory rodents. In previous studies, we reported the suppressive effects of infestation by $R$. sanguineus on antibody productivity and the neutrophil function in dogs [7, 8]. Lymphocytes are important cells in the immune system and play a central role in acquired immunity. However, the effects of tick infestation on lymphocyte function in dogs have not yet been determined. We examined the mitogen blastogenic responses of lymphocytes from dogs infested with adult $R$. sanguineus, and also the effects of salivary gland extract of the tick on the blastogenic responses of lymphocytes from normal dogs.

Twelve tick-naive, adult male Beagles bred at Yamaguchi University, Japan, and weighing between 9 and $12 \mathrm{~kg}$ were used. Dogs were infested with ticks using the ear bag method. The ticks used in this study were adult $R$. sanguineus from a colony maintained in our laboratory since 1994. Four dogs (group A) were infested with 10 pairs of adult ticks on day -60 as pre-infestation. A period of 60 days is long enough for $R$. sanguineus in an optimum condition to complete a life cycle [6]. On day 0 , the 4 dogs in group A and 4 other dogs (group B) were each infested with 10 pairs of adults in ear bags as the second and first infestation, respectively. Another 4 dogs were used as tickfree controls (group C). Female ticks were engorged on day 7 to 11 in group A and day 6 to 8 in group B. The difference of the period for engorgement between group A and $B$ was thought to be a resistance developed by repeated infestation [9]. Male ticks were also removed on days 11 and 8 in group A and B, respectively. Peripheral blood was collected with heparin $(20 \mathrm{U} / \mathrm{m} l)$ from each dog on day 0,3 , $6,9,12,15,18,21,24$ and 27 to evaluate the peripheral blood lymphocyte (PBL) responses to mitogens.

To obtain salivary gland extract (SGE) from partiallyengorged $R$. sanguineus, unfed female adults were allowed to feed for 4 days on the ears of rabbits (Japanese white, Kyudo, Japan).

A density gradient method using Lymphoprep (1.077 g/ $\mathrm{m} l$, Nycomed Pharma AS, Oslo, Norway) was used to separate PBL from peripheral blood [5]. Contaminated red blood cells were lysed with ammonium chloride Tris buffer (0.017 M Tris, $\mathrm{pH} 7.2$ containing $0.75 \% \mathrm{NH}_{4} \mathrm{Cl}$ ), washed twice with sterile PBS, and finally resuspended at $2 \times 10^{6}$ cells/ml in complete RPMI 1640 medium (ICN Biomedical Japan) containing $10 \%$ heat-inactivated fetal bovine serum (FBS, ICN Biomedical Japan), penicillin (100 IU/ml) and streptomycin $(20 \mu \mathrm{g} / \mathrm{m} l)$. Observation of PBL after Giemsa staining revealed that the cell suspensions contained less than $8 \%$ neutrophils. In addition, more than $95 \%$ of PBL were viable by trypan blue dye exclusion. Aliquots of $50 \mu l$ of PBL suspension were added in triplicate to wells in 96well microculture plates (Flow Laboratories Inc., U.S.A.) along with $50 \mu \mathrm{l}$ of an optimum concentration of concanavalin A (Con A, $2.0 \mu \mathrm{g} / \mathrm{m} l$, EY Laboratories, Inc., U.S.A.), phyto-hemagglutinin (PHA, $3.0 \mu \mathrm{g} / \mathrm{m} l$, EY Laboratories, Inc., U.S.A.) or pokeweed mitogen (PWM, $1.0 \mu \mathrm{g} / \mathrm{ml}$, EY Laboratories, Inc., U.S.A.) in complete medium. The cell cultures were incubated for $72 \mathrm{hr}$ at $37^{\circ} \mathrm{C}$ in a humidified atmosphere of $5 \% \mathrm{CO}_{2}$. The blastogenic activities of cells in culture were evaluated by an assay using 3-[4,5-dimethylthiazol-2-yl]-2,5-diphenyl tetrazolium bromide (MTT) [5, 14]. The results are expressed as stimulation index (SI) according to the following formula from the results of duplicate assays.

$\mathrm{SI}=($ O.D. $(570 / 630 \mathrm{~nm})$ of stimulated cells with FE) / (O.D. (570/630 nm) of unstimulated cells without FE)

Female $R$. sanguineus were collected from rabbits. The salivary glands were dissected out from each tick under a microscope and homogenized with a ground glass homogenizer in $2.0 \mathrm{~m} l$ of phosphate buffered saline (PBS, 
$\mathrm{pH}$ 7.2) and $5 \mathrm{mM}$ phenylmethylsulfonyl fluoride (PMSF, Nakalai Tasque, Japan) in an ice bath. This crude extract was centrifuged at $7740 \times \mathrm{g}$ for $5 \mathrm{~min}$ in a microcentrifuge (Titer Teck, Japan). The supernatant was filtered through a $0.22 \mu \mathrm{m}$ filter and the protein concentration was determined with a kit (DC Protein Assay Kit. Bio-Rad, U.S.A.). The SGE was stored at $-20^{\circ} \mathrm{C}$ until use.

To evaluate its effects on PBL responses to mitogens, SGE samples were diluted with PBS to concentrations of 4 , $20,40,80,200,400,800$ and $1,200 \mu \mathrm{g} / \mathrm{ml}$. Then, $25 \mu \mathrm{l}$ of each concentration of SGE was added in triplicate to the wells of 96-well microtiter plates containing $1 \times 10^{5}$ cells/ well of PBL from four healthy tick-naive dogs and an optimum concentrations of mitogens. The final volume in each well was $100 \mu l$. The blastogenic activities of cells in culture were evaluated by MTT assay after incubation for $72 \mathrm{hr}$.

SGE was treated with trypsin to characterize the suppressive effect of SGE on lymphocyte blastogenic responses. To digest SGE with trypsin, 1 volume of SGE solution $(2.0 \mathrm{mg} / \mathrm{m} l)$ was mixed with an equal volume of trypsin (Celox Laboratories, U.S.A.) dissolved at a concentration of $1.0 \mathrm{mg} / \mathrm{m} l$ in $0.02 \%$ EDTA (Dojindo Inc., Japan) solution, $\mathrm{pH}$ 7.4. The mixture was incubated for 30 min at $37^{\circ} \mathrm{C}$ and the reaction was stopped by adding 3 volumes of $10 \%$ heat-inactivated in RPMI 1640 medium. This mixture was tested for inhibition of the PBL responses to mitogens. Fifty $\mu l$ of the mixture was put into a well of a microtiter plate, containing PBL and mitogens. Controls consisted of PBS instead of SGE and $0.02 \%$ EDTA instead of trypsin solution. The final volume of each well was 100 $\mu l$, and the final optimum concentration of PBL and mitogens consisted of PBL: $1 \times 10^{6}$ cells $/ \mathrm{m} l$, Con A: 2.0 $\mu \mathrm{g} / \mathrm{m} l$, PHA: $3.0 \mu \mathrm{g} / \mathrm{m} l$ and PWM: $1.0 \mu \mathrm{g} / \mathrm{m} l$. The blastogenic activities of the cells in culture were evaluated by MTT assay after $72 \mathrm{hr}$ of incubation.

A non-parametric Wilcoxon signed-ranks test was performed to analyze the blastogenesis in dogs infested with ticks. A non-parametric Mann-Whitney test was used to analyze the effects of SGE on the PBL responses to mitogens and the effects of trypsin digestion on the immune modulating ability of SGE. The difference was thought to be significant at the level of 0.05 .

The results of the blastogenic response of PBL from tick infested or control dogs to Con A, PHA and PWM are shown in Fig. 1a, b and c, respectively. The 3 mitogen responses of PBL from dogs of group A (the second infestation) decreased on day 3,6 and 9 compared with day 0 . But the differences were not statistically significant. On day 12 when all the ticks dropped off the hosts, the PBL responses to mitogens were recovered to the level of day 0 . In group B (the primary infestation), the decreased responses of PBL were more clear than those of group A. The Con A and PHA responses of PBL were decreased significantly on day 3, 6, 9, 12 and 15 when compared with day 0 . While the PWM response in group B decreased significantly on day $3,6,9$ and 12, the PBL responses of control dogs in
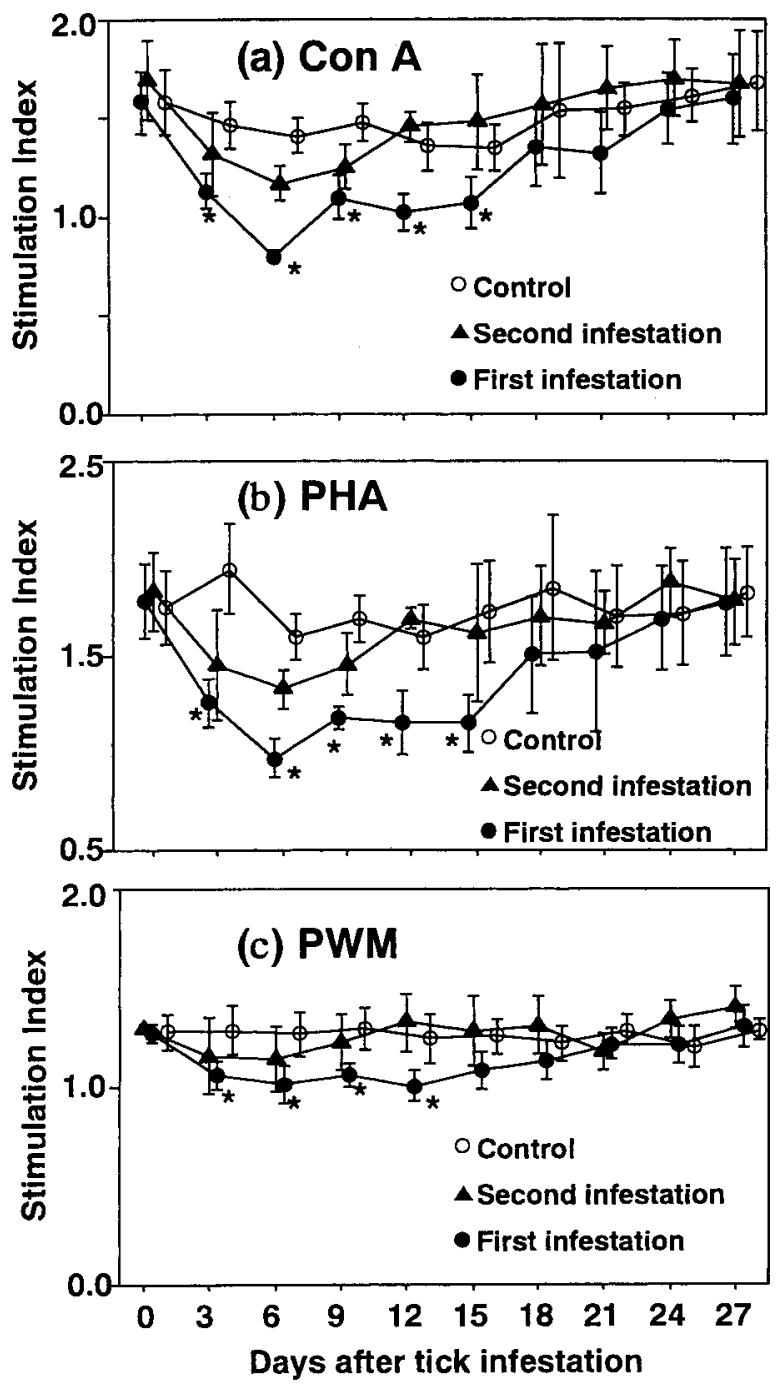

Fig. 1. Effects of infestation with Rhipicephalus sanguineus on the blastogenic responses of dog peripheral blood lymphocytes to Con A (a), PHA (b) and PWM (c). Symbols indicate the means of results from experimental (the first and second infestation with the ticks) and control dogs. Short vertical bars represent standard errors. Ticks were put in an ear bag and applied to each dog on day 0 . Ticks were engorged on day 7 to 11 in dogs with the second infestation, and on day 6 to 8 in the dogs with the first infestation. Stars show significant differences $(\mathrm{p}<0.05)$ from day 0 .

group $\mathrm{C}$ did not show any significant changes. We used three mitogens for the assay. Con A and PHA are known to be T lymphocyte mitogens and PWM is effective to both T and $\mathrm{B}$ lymphocytes. The result suggested that at least mitogenic responses of $\mathrm{T}$ lymphocytes from dogs were suppressed by the infestation with $R$. sanguineus. However suppression of B lymphocytes by the tick infestation were not determined. Similar suppression of T lymphocyte proliferation caused by tick infestation have been reported in the experimental animals or cattle [5, 11, 16-18, 21]. Our recent results support those findings. 
In this study, the inhibition of PBL responses of dogs in the first infestation was greater than those in the second infestation. The same finding was reported in the guinea pigs infested with Dermacentor andersoni [21]. It is suspected that repeated infestation of the tick induced antibodies to some immune suppressive factors from the tick. More recently, Wikel et al. [25] reported that the host immune response to repeated tick feeding could possibly neutralize immunosuppressive molecules introduced by the tick. On the other hand, findings that the suppressive effect of repeated tick infestation was greater than those of the first infestation, were also reported [4, 5, 20]. Tick saliva also contains soluble antigens which can trigger a $\mathrm{T}$ lymphocyte specific response in BALB/c mice infested with ticks [12]. Both suppression and stimulation of $\mathrm{T}$ lymphocyte responses may occur at the same time in a host animal, but more studies are needed to clarify the findings. Saliva is one of candidates for the origin of the immune suppressive factors from the ticks. In group B (the primary infestation), the peak of the suppression was found on day 6 prior to the engorgement of female ticks. As the protein concentration in saliva increases before engorgement [19], the suppressive activity may concern with the proteins from salivary gland.

In the second experiment, suppressive effects of SGE on the blastogenic response of PBL from healthy dogs to Con A, PHA and PWM were observed as shown in Fig. 2a, b and c, respectively. Significant suppression was observed for Con A and PWM responses at the concentration of more than $100 \mu \mathrm{g} / \mathrm{m} l$ and PHA responses at more than $50 \mu \mathrm{g} / \mathrm{m} l$. The suppressive effects seem to be dose-dependent at such a high concentration, however there was no suppression at low concentration of SGE. The results suggested that lymphocyte response, especially $\mathrm{T}$ lymphocyte from dogs was suppressed by SGE of $R$. sanguineus. Similar phenomenon of $\mathrm{T}$ cell suppression by tick saliva or SGE was observed in mice [16] or cattle [17] infested with $D$. andersoni, in cattle infested with Boophilus microplus [5] and in mice infested with Ixodes dammini [18].

In the third experiment, SGE was subjected to trypsin digestion to evaluate the characteristics of the immune suppressive activity. The suppressive effects of SGE on the blastogenic responses of PBL to Con A, PHA and PWM were significantly inhibited by trypsin digestion. These results suggested that some proteins in SGE may contribute to the suppressive effects of SGE on the blastogenic responses of dog PBL. Bergaman et al. [2] studied the salivary gland proteins from $D$. andersoni which suppressed $\mathrm{T}$ lymphocyte responses, and found that proteins with molecular weights ranging from 36 to $43 \mathrm{kd}$ suppressed mouse splenocyte proliferation response to Con A. Urioste et al. [18] also reported that a protein with a molecular weight of $5 \mathrm{kd}$ or higher was responsible for the inhibition of mouse splenic $\mathrm{T}$ lymphocyte proliferation. The immune suppressive proteins in $R$. sanguineus should be examined in more detail in future studies.

Recently, the cytokine-mediated mechanism of immune
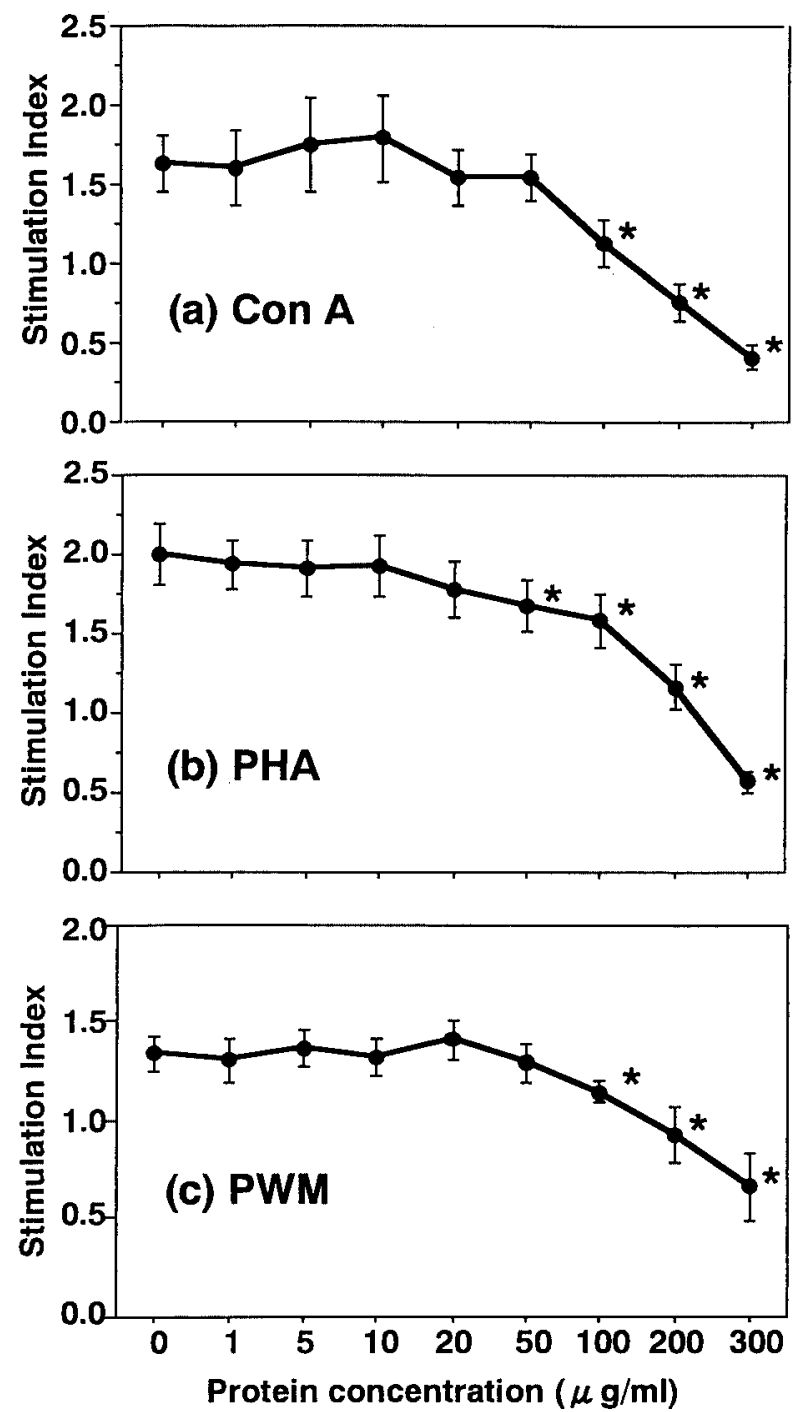

Fig. 2. Effects of salivary gland extract (SGE) from partly engorged females of Rhipicephalus sanguineus on the blastogenic responses of dog peripheral blood lymphocytes to Con A (a), PHA (b) and PWM (c). Cells $\left(1 \times 10^{6}\right.$ cells $\left./ \mathrm{m} l\right)$ were cultured with optimal concentrations of Con A $(2.0 \mu \mathrm{g} /$ $\mathrm{m} l)$, PHA $(3.0 \mu \mathrm{g} / \mathrm{m} l)$ or PWM $(1.0 \mu \mathrm{g} / \mathrm{m} l)$ and various concentrations of SE or PBS as controls. Symbols represent the means \pm standard error of the blastogenic responses of peripheral blood lymphocytes from 4 healthy dogs. Stars show significant differences $(\mathrm{p}<0.05)$ from control.

suppression by tick infestation has been demonstrated in the experiments in mice $[11,17,18,22]$. However, the detailed mechanism of suppression of the lymphocyte blastogenic responses in dogs infested with $R$. sanguineus has not been determined. This phenomenon may play an important role in the transmission of many tick-borne diseases, because $R$. sanguineus is a well known vector of Babesia canis [10], $B$. gibsoni [10], Hepatozoon canis [3], Ehrlichia canis [13], spotted fever group Rickettsiae [1] and Dipetalonema spp filaria [15]. The suppressive effects of tick saliva on the 
Table 1. Effects of trypsin digestion on the suppressive effect of salivary gland extract (SGE) on the blastogenic responses of peripheral blood lymphocytes from healthy dogs

\begin{tabular}{lccc}
\hline & \multicolumn{3}{c}{ SGE treatment } \\
\cline { 2 - 4 } Mitogens & SGE without trypsin & SGE with trypsin & PBS with trypsin \\
\hline Con A & $0.982 \pm 0.038$ & $1.350 \pm 0.061^{*}$ & $1.310 \pm 0.059^{*}$ \\
PHA & $1.264 \pm 0.058$ & $1.561 \pm 0.072^{*}$ & $1.623 \pm 0.067^{*}$ \\
PWM & $0.934 \pm 0.030$ & $1.176 \pm 0.067^{*}$ & $1.239 \pm 0.068^{*}$ \\
\hline
\end{tabular}

Results are means \pm standard errors of the stimulation index from four healthy dogs. *: Significantly different $(\mathrm{p}<0.05)$ compared with SGE without trypsin.

lymphocytes may also contribute to the decreased antibody productivity or neutrophil functions that we reported previously [7, 8].

\section{REFERENCES}

1. Beati, L., Ronx, V., Ortuno, A., Castella, J., Porta, F. S. and Raoult D. 1996. J. Clin.Microbiol. 34: 2688-2694.

2. Bergaman, D.K., Ramachandra, R.N. and Wikel, S.K. 1995. Exp. Parasitol. 81: 262-271.

3. Craig, T.M. 1990. pp 778-785. In: Infectious Deseases of the Dog and Cat (Greene, C.E. ed.), WB Saunders Co., Philadelphia.

4. Dusbabek, F., Borsky, I., Jelinek, F. and Uhlir, J. 1995. Med. Vet. Entomol. 9: 133-140.

5. Inokuma, H., Kerlin, R.L., Kemp, D.H.and Willadsen, P. 1993. Vet. Parasitol. 47: 107-118.

6. Inokuma, H., Tamura, K. and Onishi, T. 1996. J. Vet. Med. Sci. 58: 225-228.
7. Inokuma, H., Aita, T., Tamura, K. and Onishi, T. 1997. Med. Vet. Entomol. 11: 201-202.

8. Inokuma, H., Hara, Y., Aita, T. and Onishi, T. 1997. Med. Vet. Entomol. 11: 401-403.

9. Inokuma, H., Tamura, K. and Onishi, T. 1997. Vet. Parasitol. 68: 295-297.

10. Kuttler K.L. 1988. pp. 1-22. In: Babesiosis of Domestic Animals and Man (Ristic M. ed.), CRC Press Inc., Florida.

11. Ganapamo, F., Rutti, B. and Brossard, M. 1996. Immunology 87: 259-263.

12. Ganapamo, F., Rutti, B. and Brossard, M. 1997. Parasitology 115: 91-96.

13. Groves, M.G., Dennis, G. L., Amyx, H.L. and Hursll, D.L. 1975. Am. J. Vet. Res. 36: 937-940.

14. Mossman, T. 1983. J. Immunol. Methods 65: 55-63.

15. Olmeda-Garcia, A.S., Rodriguez-Rodriguez J.A. and RojoVazq, F.A. 1993. Vet. Parasitol. 47: 339-342.

16. Ramachandrta, R.N and Wikel, S.K. 1992. J. Med. Entomol. 29: 818-826.

17. Ramachandrta, R.N and Wikel, S.K. 1995. J. Med. Entomol. 32: $338-345$.

18. Urioste, S., Hall, L.R., Telford S.R. III and Titus, R.G. 1994. J. Exp. Med. 180: 1077-1085.

19. Wang, H. and Nuttall, P.A. 1994. Parasitology 109: 517523.

20. Wikel, S.K. and Osburn, R.L.1982. Ann. Trop. Med. Parasitol. 76: 405-414.

21. Wikel, S.K. 1982. Ann. Trop. Med. Parasitol. 76: 627-632.

22. Wikel, S.K. 1996. Ann. Rev. Entomol. 1: 1-22.

23. Wikel, S.K. 1996. Exp. Parasitol. 84: 304-309.

24. Wikel, S.K. and Bergman, D. 1997. Parasitol. Today 13: 383-389.

25. Wikel, S.K., Ramachandrta, R.N., Bergman, D.K., Burkot, T.R. and Piesman, J. 1997. Inf. Immun. 65: 335-338. 